\title{
Thermal Manikin of Infant
}

\section{Yoshihito Kurazumi ${ }^{1}$, Tomonori Sakoi ${ }^{2}$, Ken Yamashita ${ }^{3}$, Kenta Fukagawa ${ }^{4}$, Emi Kondo5, Tadahiro Tsuchikawa ${ }^{6}$}

\author{
${ }^{1}$ School of Life Studies, Sugiyama Jogakuen University, Nagoya, Japan \\ ${ }^{2}$ Academic Assembly, Institute of Textile Science and Technology, Shinshu University, Ueda, Japan \\ ${ }^{3}$ School of Life Studies, Sugiyama Jogakuen University, Nagoya, Japan \\ ${ }^{4}$ Department of Architecture, Kyushu Sangyo University, Fukuoka, Japan \\ ${ }^{5}$ Department of Architecture, Ariake National College of Technology, Omuta, Japan \\ ${ }^{6}$ School of Human Science \& Environment, University of Hyogo, Himeji, Japan \\ Email:kurazumi@sugiyama-u.ac.jp
}

How to cite this paper: Kurazumi, Y., Sakoi, T., Yamashita, K., Fukagawa, K., Kondo, E. and Tsuchikawa, T. (2019) Thermal Manikin of Infant. Engineering, 11, 735-754. https://doi.org/10.4236/eng.2019.1111048

Received: October 7, 2019

Accepted: October 26, 2019

Published: October 29, 2019

Copyright ( 2019 by author(s) and Scientific Research Publishing Inc. This work is licensed under the Creative Commons Attribution International License (CC BY 4.0).

http://creativecommons.org/licenses/by/4.0/ (c) (i) Open Access

\begin{abstract}
Compared to an adult, an infant requires more consideration regarding the thermal environment so it is necessary to evaluate the thermal environment as it affects infants. However, experiments on infant subjects regarding their thermal environment based on the different heat balance of their body cannot ethically be conducted. We could instead consider using a thermal model for the human body, but thermal manikins based on heat transfer per unit area are rare. Therefore, this study aims to develop a thermal manikin to model the heat transfer per unit area and the body form of an infant in order to evaluate the infant's thermal environment. When evaluating the thermal environment or heat balance of the body in the outside environment, it is essential to consider the asymmetry and unevenness of the temperature of the skin, as an element of the human body, and not just the unevenness and asymmetry of physical factors in the environment. Moreover, when receiving short wavelength direct solar radiation, light and shaded areas have significant differences in skin temperature. The following 20 body parts were investigated in the study: anterior head, posterior head, ventral trunk, dorsal trunk (including buttocks), right medial arm, right lateral arm, left medial arm, left lateral arm, right dorsal hand, right palmar hand, left dorsal hand, left palmar hand, right anterior leg, right posterior leg, left anterior leg, left posterior leg, right dorsal foot, right plantar foot, left dorsal foot, and left plantar foot. This paper measured the body surface area for each part of an infant's body in order to establish the form of an infant model from the view of the heat transfer area, and verified the validity of the model.
\end{abstract}

\section{Keywords}

Heat Balance, Heat Transfer Area, Infant, Outdoor, Thermal Environment, 


\section{Introduction}

Harmful changes to the outside environment due to global warming or the heat island phenomenon in cities are a problem. Considered on a familiar weather scale, the city heat island is a core environmental problem and has three main causes: an increase in artificial waste heat, artificial ground covering and the high density of urban morphology. Problems affecting the human body such as heat stroke, disturbed sleep and air pollution are caused by the heat island phenomenon [1].

Effects on the human body caused by the outside environment have been quantitatively clarified in terms of the results of the thermal sensation by the human body of external thermal environmental elements using the ETFe environmental evaluation index proposed by Kurazumi et al. [2], which can calculate the temperature for individual factors of the outside thermal environment. $\mathrm{Ku}$ razumi et al. [3] clarified that the factors influencing the thermal sensation of the human body in the summertime outside environment include heat conduction, humidity and short wavelength solar radiation, while the factors influencing the thermal comfort of the human body are air flow, heat conduction and humidity. Kurazumi et al. [4] next clarified the factors influencing the thermal sensation of the human body in the wintertime outside environment, listing the air temperature, long wavelength radiation and short wavelength solar radiation, while the factors influencing the thermal comfort of the human body in wintertime are air temperature, humidity, short wavelength solar radiation, long wavelength thermal radiation, and heat conduction.

Kurazumi et al. [5] [6] [7] qualitatively clarified the effect that strong short wavelength solar radiation in tropical climates has on the thermal sensation of the human body when applying the outside thermal environment evaluation index ETFe [2]. It clarifies that in tropical areas where the effects of nighttime cooling cannot be expected, the effect of long-wave length thermal radiation is strong in the shade of objects made of materials with high heat capacity, and the effect of improving the thermal sensation of the human body through shade is low. This research shows the necessity to eliminate the influence of long wavelength thermal radiation in poor outside thermal conditions.

In summertime outside spaces, long wavelength thermal radiation from the ground surface and short wavelength solar radiation strongly influence the human body, further heating the body and increasing the risk of thermal injury due to heat stroke, etc. To reduce this, it is essential to alleviate the influence of short wavelength solar radiation by moving into shade. However, due to the difficulty in escaping the influence of long wavelength thermal radiation from the ground, it is necessary to take drastic measures, such as adding natural water or greenery features to areas of artificial paving. Alternatively, we may be forced to move in 
order to reduce the angle factor between the human body and the ground surface.

Compared to healthy people or adults, the elderly, physically disabled (people with spinal cord injuries, etc.) and children cannot adapt easily to heat from the environment. The summertime outside environment places a heavy load on body temperature regulation and increases the need for measures to counter the thermal stress. Universal accessibility is progressing and public facilities are assumed to have wheelchair or stroller access. Usually, a parent going outside with their infant would have to carry them, but with the development of universal access, physical obstacles such as roads and facilities have been mitigated, making it easier to go outside with a stroller. Therefore, the social environment has removed the physical labor of carrying an infant, making it easier for parents to go outside with their children. An infant in a stroller is more susceptible to short wavelength solar radiation from the sky and long wavelength thermal radiation from the ground. Since strollers are close to the ground, they are considered to be strongly influenced by reflected solar radiation from the ground and long wavelength thermal radiation.

Infants characteristically heat up easily in hot environments and cool easily in cold environments [8]. Therefore, infants are considered to feel and adapt to the environment in different ways from adults [8] [9]. Compared to adults, the body surface area of an infant is extremely small, giving them an extremely large body surface area to weight ratio. Therefore, the heat transfer for regulating the body temperature is important [10].

There is a lack of research on the bodily response of an infant in a thermal environment. Although there is research regarding the amount of sweat in body temperature regulation, there is no clear trend in the amount of sweat from an adult compared to an infant, and it is considered to differ with maturity [11] [12] [13] [14] [15]. Also, a relationship between the density of sweat glands and heat conduction has been reported [10].

In analyzing the above relations, for infants there is less thermal radiation for body temperature regulation due to their large body surface area to weight ratio compared to adults [15] [16] [17] [18] [19].

Research on the skin's heat response to thermal stimuli shows that the mean skin temperature is higher in infants than adults [11] [13] [20] [21] [22]. Therefore, the cooling speed of the body is lower for a child than for his/her mother, showing the possibility of a lower ability to produce sweat. Since an infant has lower thermal responsivity and a poor ability to regulate his/her body temperature, it is necessary to evaluate more body parts in studies [21].

There is a large amount of researches relating to the thermal environment of infants, wherein regulation from cooling or heating devices and the amount of clothing needed to match the infant's daily rhythm are shown to depend on the thermal environment that the mother is exposed to [23] [24]. Thus, the parent has a major influence on the form of thermal environment that the infant experiences [25]. In any case, it is necessary to be careful of the possibility that the air 
temperature distribution that the infant is actually exposed to differs from that of the mother. However, since the thermal balance in the body of an infant has not been evaluated, the analysis and response is still insufficient. As infants cannot report their own condition due to immaturity or their inability to communicate, their thermal environment is inevitably influenced by the judgement of the parent.

The above is based on reports from research regarding the thermal environment of infants, which suggests that infants experience a worse thermal environment than adults. Because an infant's thermal environment or body temperature regulation differs from an adult, it is essential to take into account the differing thermal influences as a basis for evaluating the actual thermal environment. However, we cannot ethically conduct experiments on infant subjects to determine these differences. Here, therefore, this research aims to develop a thermal manikin modelling the heat transfer per unit area and the body form of an infant in order to evaluate the thermal environment for an infant. The surface area of each part of an infant's body was measured in order to establish the form of an infant model, and the validity of the model was clarified.

\section{Thermal Model for the Human Body}

To examine the thermal exchange between an infant's body and the environment, we can use a thermal manikin or numerical manikin. However, neither the relationship between the generated and radiated heat nor the human form, boundary conditions or coefficient values are clear for the human body using a numerical manikin.

Many numerical manikins have been developed to model the thermal regulation of the human body. Methods include the comparatively simple cylindrical model from Wissler [26], the improved Wissler model of Atkins and Wyndham [27] and the Two-node model of Gagge et al. [28] [29] [30]. Also, methods that have the human form include those reported by Stolwijk and Hardy [31], Stolwijk [32], Smith [33], Takemori et al. [34], Fu [35], Yokoyama et al. [36] [37] [38], Tanabe et al. [39], Huizenga et al. [40], McGuffin et al. [41], Kohri and Mochida [42], Ozeki et al. [43], Sakoi et al. [44], Kuwabara et al. [45], Park and Tuller [46], and Kurazumi et al. [47]. However, for each model, the input values for the physiological response or the coefficient values for the body's thermal environment specifically for an infant are unclear, and the thermal environment of an infant cannot be evaluated.

However, if the heat transfer characteristics of the thermal environment for a thermal manikin are known, the influence of the thermal environment on an infant's body can be evaluated. Many adult thermal manikins are commercially available, including those from Kyoto Electronics Manufacturing Co., Ltd. [48], Measurement Technology North West Thermetrics [49], Intec Co., Ltd. [50], and PT-Teknik [51], and Measurement Technology North West Thermetrics [49] also sell an infant thermal manikin. Further, other companies are able to make products to order. However, orders for thermal manikins are extremely 
small. For example, Kyoto Electronics Manufacturing Co., Ltd. [48] made five infant thermal manikins per month as a pilot job [52], while Measurement Technology North West Thermetrics [49] develops and sells infant manikins at nine pieces per month. However, these are made based on the dimensions of the human body and not on the heat transfer per unit area.

From the above, as concerns the thermal environment for an infant, we could consider using a thermal model for the human body, but thermal manikins based on heat transfer per unit area are rare.

\section{Experimental Plan}

The heat transfer area includes the convective heat transfer area, radiative heat transfer area and conductive heat transfer area. However, in this research, there is no contact between body parts and the entire body is exposed to air flow, making convective heat transfer area the dominant process for the whole body [53] [54] [55]. Body surface area was directly measured by attaching surgical tape directly to the body surface and calculating the area of the tape [53] [54] [55] [56] [57].

Non-woven surgical tape was directly attached so as to overlap (Nichiban: Nichiban Surgical Tape-21N, $12 \mathrm{~mm}, 25 \mathrm{~mm}, 50 \mathrm{~mm}$ ). After the overlapping portions were marked with a pen, they were carefully removed and attached to Kent paper. We used an in-house computer program and a digitizer (Graphtec: KD4310, resolution: $0.025 \mathrm{~mm}$ ) to calculate the area of tape excluding the overlapping tape portions.

Human models developed from electronic information technology or calculation technology are used in the field of CG animation, for example. Human models developed from IT, including modeling technology, rendering technology or motion expression technology and even action modeling technology, are used as a visual model of the body in many fields such as animated movies, virtual reality or video games. There is also research to replicate the body, including internal organs, that uses CT (computed tomography) or MRI (magnetic resonance imaging), as used in medical imaging. A human model is currently being made with a resolution on the millimeter scale. Although the application of a numerical simulation that clarifies biological effects is being considered, the expression of heat exchange by the body from the surrounding environment has not been investigated.

It is necessary to investigate the precision of a human model by considering the state of the body or of the environment. Thus, it is essential to define the appropriate boundaries of the body model. There are many $3 \mathrm{D}$ forms recreating the human body with simplifications that replace the body with geometric shapes.

When examining the heat exchange between the human body and the surrounding environment, a human model that can express the details of the size and surface form of the body is necessary. Human models that express the details of the human form include those of Suzuki and Kakitsuba [58], Ozeki et al. 
[59], Manabe et al. [60], Omori et al. [61], Sørensen et al. [62], Torii et al. [63], Ito and Hotta [64], and Kurazumi et al. [65]. All of these models are of an adult. Suzuki and Kakitsuba [58] made a human body model in a standing position that uses a sliding gauge. The validity of the model was clarified by running a comparison of the body surface area, effective radiation area factor and angle factor from the model with a real human. Ozeki et al. [59] used commercially available body modeling software to make human models out of small square elements; these were in a standing position, seated and cross-legged positions. The validity of this method was confirmed by Fanger et al. [66] and Tsuchikawa et al. [67] through comparison with the results of measurements on the human body using the angle factor and effective radiation area factor of the human model using parallel light rays. However, the differences in human form, rather than models that measure the body, have not been investigated. Manabe et al. [60] made a standing humanoid model formed from triangles by using wires to measure cross-sections of the human body. However, this method has not been verified. Omori et al. [61] made a human model that imitates the form of a thermal manikin with non-contacting body parts, but there is no explanation of the making process, and its validity has not been investigated. Sørensen et al. [62] used a non-contact 3D digitizer to make a humanoid model imitating the form of a thermal manikin in a seated position formed from small triangular elements. The validity of the surface area was clarified through comparison with the area of a 16-piece thermal manikin and that of a humanoid model. However, again, the differences in human form, rather than models that measure the body, were not investigated. Torii et al. [63] also used a non-contact 3D digitizer to make a humanoid model in a standing position formed from small triangular elements. The validity of the body surface area was clarified through comparison of a human body with the body surface area, convective heat transfer area, radiative heat transfer area, conductive heat transfer area, and angle factor of a humanoid model. Ito and Hotta [64] used commercially available body modeling software to make a humanoid model from many triangular elements. However, differences in human form were still not investigated. There is a humanoid model that targets the heat exchange from radiation and convection of the human body with the surrounding environment. Kurazumi et al. [65] used a non-contact 3D digitizer to make a seated humanoid model formed from small triangular elements. The validity of this was confirmed through comparison of a human body with the body area, convective heat transfer area, radiative heat transfer area and conductive heat transfer area of a humanoid model.

For the humanoidmodels above, investigations have been done from the perspective of the radiative heat transfer or surface area of a body. However, apart from the humanoid models designed by Suzuki and Kakitsuba [58], Torii et al. [63] and Kurazumi et al. [65], they are not based on actual measurements and the scientific basis is rarely reported. Thus, humanoid models made to measure the heat balance of the human body are extremely rare. In addition, no investigations of models based on infants have been done. 
As mentioned in the introduction, while numerical manikins that are heat exchange models of the body and design or evaluation methods of the thermal environment from humanoid models using numerical calculations are mainstream, many of the boundary conditions or coefficient values for the body form of an infant, which differs from an adult, have not been clarified. Therefore, making a quantitative analysis of a numerical humanoid model for an infant could be difficult.

We cannot ethically conduct experiments on infant subjects to clarify their thermal environment based on the heat balance of the body, so we use an infant humanoid model as a subject for thermal manikin modeling. The medical and nursing fields use the infant humanoid model known as Nurse Training Baby (3B Scientific: W17002, Asian Body Care Model male) by Nihon 3B Scientific Inc. [68]. This Nurse Training Baby is formed from a head, trunk (including buttocks), upper limbs, and lower limbs based on dedicated modeling. The body is approximately $50-60 \mathrm{~cm}$ long. The validity of the heat transfer area has been investigated for this Nurse Training Baby.

For measurements of the body surface area, there are 18 parts for both the left and right of each section, including the head, ventral trunk, dorsal trunk (including buttocks), upper arm, forearm, hand, thigh, leg, and foot.

\section{Experimental Results}

Table 1 shows the experimental results for the surface area of each section. The total body surface area is $2087.50 \mathrm{~cm}^{2}$. The surface area ratio for each of the main body parts, which are the head, trunk (including buttocks), arm, hand, leg and foot, were $0.238,0.302,0.117,0.041,0.240$ and 0.062 respectively. This shows the large head to body surface ratio that is characteristic of newborn babies and infants. As about shown in Figure 1 later, the subject's right hand is closed. However, the subject's left hand is opened. As a result, the body surface area of the left hand was larger than that of the right hand.

In body surface area research, there are many surface area measurements with no left-right variation. However, in the results from this research a slimming trend was seen in the right lower limbs when compared to the left lower limbs.

\section{Effectiveness of the Infant Model Body}

The surface area of the body was calculated with a process for devising a formula for the area. Many studies have been conducted since Funke's measurements of surface area [69]. DuBois' expression [70] for calculating body surface area has been widely employed. However, even with the DuBois' formula [70], surface area measurements have been made for only 12 people [71] [72]. In addition, a surface area formula was proposed that measures only half of the surface area of a left-right body [70].

In Japan, the formula for calculating body surface area from Fujimoto et al. is widely used [73]. However, due to the large differences in form or physique 
Table 1. Results of body surface area.

\begin{tabular}{|c|c|c|c|}
\hline Reagion & Surface area $\left[\mathrm{cm}^{2}\right]$ & Area ratio [-] & Area ratio $[-]$ \\
\hline Right head & 256.29 & 0.123 & 0.238 \\
\hline Left head & 240.53 & 0.115 & \\
\hline Right ventral trunk & 155.25 & 0.074 & 0.302 \\
\hline Left ventral trunk & 151.31 & 0.073 & \\
\hline Right dorsal trunk & 154.99 & 0.074 & \\
\hline Left dorsal trunk & 168.01 & 0.081 & \\
\hline Right upper arm & 61.66 & 0.030 & 0.117 \\
\hline Left upper arm & 60.71 & 0.029 & \\
\hline Right forearm & 59.61 & 0.029 & \\
\hline Left forearm & 60.87 & 0.029 & \\
\hline Right hand & 34.80 & 0.017 & 0.041 \\
\hline Left hand & 49.03 & 0.024 & \\
\hline Right thigh & 146.78 & 0.070 & 0.240 \\
\hline Left thigh & 159.07 & 0.076 & \\
\hline Right leg & 91.86 & 0.044 & \\
\hline Left leg & 105.32 & 0.050 & \\
\hline Right foot & 67.78 & 0.032 & 0.062 \\
\hline Left foot & 63.63 & 0.030 & \\
\hline
\end{tabular}

arising from variations in lifestyle or diet in Japan, the measurement data and actual conditions that the formula is based on are remarkably different. Kurazumi et al. [57] compared the body surface area formulas from DuBois [70], Fujimoto et al. [73] and Kurazumi et al. [56] with the measured results of the body surface area of Japanese people. They found that the formula from Kurazumi et al. [56] was most effective given the differences in people's form and physique. This formula for body surface area is now the standard for AIJES-H0004-2014 (Standards for Measurement of Psychological and Physiological Responses to Thermal Environments) of the Architectural Institute of Japan [74].

Meeh [75] made early measurements of the body surface area for two infants. The measurements were made on one side only, assuming the left-right symmetry of the body. Lissauer [76] measured 12 (deceased) infants, making measurements on one side only based on the left-right symmetry of the body, but the body surface area for each section of the body is not clear. Lassabliére [77] measured 12 infants, again on one side only, but the surface area is not clear for each section of the body. Klein and Scammon [78] later measured the surface area of each body part for 7 (deceased) fetuses and 1 newborn. Otani [79] measured the body surface area of each body part for two infants, who were hospitalized and with nutritional problems. The measurements were again made on one 
side only, assuming the left-right symmetry of the body, and the surface area of each section of the body was not clear. Likewise, Oshiro and Tagawa [80] measured the surface are of six healthy infants, measuring only one side of the body. Ochi and Higuchi [81] measured the surface area of each body part for nine newborns. Kawabata [82] measured the body surface area of each body part for one infant. Kobayashi et al. [83] measured the body surface area of each body part for four healthy infants, again on one side only. Miyajima [84]measured the surface area of each body part for 12 infants aged between 0 and 12 months, but on one side only. Then, Fujimoto et al. [85] compared the surface area of each body part by age by integrating the results from Kawagoe [86], Matsuo [87], Koashi [88], Miyajima [84], and Fujiwara [89]. From the above, it is evident that research on the body surface area of infants is lacking, and it is rare for body parts.

Research regarding infants includes many body donations. For research into infant surface area, Oshiro and Tagawa [80], Kobayashi et al. [83], and Miyajima [84] measured the surface area for bodies without assuming left-right symmetry, but even in conventional research, many estimations are still made by measuring only one side of the body. Here, in order to investigate the effectiveness of infant humanoid models, Table 2 shows a comparison of past research that measured infant bodies [80] [81] [83] [84]. Compare to the above studies, the subject in this study has a small body surface area ratio of the upper limbs of the arms and the hands, but are considered to be in the range of the actual measurements in previous studies.

The body length of Japanese infants from birth to 12 months is about $50-75$ $\mathrm{cm}$ for the $50^{\text {th }}$ percentile, and the weight of infants is about $3-9 \mathrm{~kg}$ for the $50^{\text {th }}$ percentile [90]. Infant physique varies greatly with each passing month. In view of the body length of the subjects, the subject is estimated to be about $1-2$ months old. Therefore, this is considered to be similar to the results of research by Ochi and Higuchi [81], who looked at newborns.

Body surface area formulas were proposed by Lissauer [76], Otani [79], Lassabliére [77], Boyd and Scammon [91], Oshiro and Tagawa [80], Kobayashi et al. [83], and Fujimoto et al. [73]. Height, bust and weight are functional elements in the formula for body surface area. From the body length of subjects for Nurse Training Baby [68] from Nihon 3B Scientific Inc. of around $50-60 \mathrm{~cm}$, and the infant growth census conducted by the Ministry of Health, Labor and Welfare of Japan [90], the $50^{\text {th }}$ percentile of $1-2$ month old infants have a length of $55.6 \mathrm{~cm}$ and a weight of $4.79 \mathrm{~kg}$. Table 3 shows the calculated results for body surface area from this data. As there is a difference in the health and age of the subjects on which the body surface area is based, the results show a wide distribution. Compare to the above studies, the subject in this study is considered to be in the range of the actual measurements in previous studies.

From the above, and based on the Nurse Training Baby, we can say that the validity of the thermal manikin modeling of an infant has been investigated. 
Table 2. Comparison of measured body surface area ratio.

\begin{tabular}{cccccc}
\hline Reagion & Authers & Ochi & Oshiro & Kobayashi & Miyajima \\
\hline Head & 0.238 & 0.254 & 0.204 & 0.199 & 0.185 \\
Trunk & 0.302 & 0.248 & 0.272 & 0.314 & 0.366 \\
Arm & 0.117 & 0.143 & 0.185 & 0.134 & 0.126 \\
Hand & 0.041 & 0.053 & & 0.050 & 0.052 \\
Leg & 0.240 & 0.243 & 0.339 & 0.240 & 0.206 \\
Foot & 0.062 & 0.059 & & 0.063 & 0.065 \\
\hline
\end{tabular}

Ochi is Ochi and Higuchi (1935) [81]; Oshiro is Oshiro and Tagawa (1936) [80]; Kobayashi is Kobayashi et al. (1952) [83]; Miyajima is Miyajima (1960) [84].

Table 3. Comparison of calculated body surface area.

\begin{tabular}{ccccccccc}
\hline Researcher & Lissauer & Otani & Lassabliére & Boyd & Oshiro & Kobayashi & Fujimoto & Authers \\
\hline $\begin{array}{c}\text { Surface area } \\
{\left[\mathrm{cm}^{2}\right]}\end{array}$ & 2926.81 & 3091.23 & 2983.64 & 3158.09 & 3066.46 & 3101.56 & 1785.92 & 2087.50 \\
\hline
\end{tabular}

Lissauer is Lissauer (1903) [76]; Otani is Otani (1907) [79]; Lassabliére is Lassabliére (1910) [77]; Boyd is Boyd and Scammon (1930) [91]; Oshiro is Oshiro and Tagawa (1936) [80]; Kobayashi is Kobayashi et al. (1952) [83]; Fujimoto is Fujimoto et al. (1968) [73].

\section{Thermal Manikin Modeling of an Infant}

As mentioned in the previous section, the Nurse Training Baby is an effective model of an infant. However, there was a remarkable left-right difference in the legs of this humanoid model.

Due to the small influence of short wavelength direct solar radiation in the inside environment or outside shaded environment, neither is noticeably uneven or asymmetric. However, in the sunny outside environment, any part of the body may be both shaded and sunlit, which can cause a remarkable difference in skin temperature due to the effects of short wavelength solar radiation.

Horikoshi et al. [92] and Kurazumi et al. [93] ran experiments with uneven and asymmetric subjects in the indoor environment and for an uneven asymmetric thermal radiation environment; the local thermal radiation was seen to affect the psychological response, showing that there is a fluctuation in this response. Kurazumi et al. [94] showed the parameters for uneven and asymmetric thermal environment factors that can be indicators with which to evaluate the effects on the human body of an uneven asymmetric thermal radiation environment. The effects of these parameters were shown to cause a large spread in the body's response. Namely, as well as the psychological response to thermal action in indoor spaces, a large spread in thermal sensitivity in outdoor space arises from the effects of other environmental stimuli.

From the above, when evaluating the thermal environment or heat balance of the body in the outside environment, it is essential to consider the asymmetry and unevenness of the skin temperature, as an element of the human body, and not just the unevenness and asymmetry of physical factors in the environment. 
Therefore, it is desirable to have mirror images in the left and right limbs of a humanoid model. Therefore, as shown in the results section, we made a mirror image of the right side limbs based on the left limbs of the Nurse Training Baby, which is considered a healthy subject for modeling.

We used a non-contact 3D scanner (SHINING 3D: EinScan-S, resolution 0.05 $\mathrm{mm}$ ) [95] to scan around the whole infant subject model and obtained coordinate data for every point on the surface. In order to remove dimples or limb combinations, the scan was run separately for the head, trunk, arms and legs.

The thermal manikin had a three-layer structure, comprising the humanoid model, heating layer and temperature measuring layer. Figure 2 shows a crosssection of the thermal manikin. A manganin heating circuit and an alumel temperature measuring circuit were sandwiched between the three layers of insulation. The manganin wires and alumel wires were arranged to cover the whole body evenly, with the manganin wires on the inside and the alumel wires arranged on the surface. In conventional thermal manikins, the heating wire is used also to measure the temperature, which means that the measured surface temperature is higher than the onset temperature. In the proposed thermal manikin system, the heating wire is separate from the measuring wire, and enables the average temperature to be measured for the whole surface.

Kurazumi et al. [96] showed a significant difference in skin temperature in light and in shade, even for body parts that had both lit and shaded areas when receiving short wavelength direct solar radiation. As well as having mean skin temperature measurements or thermal manikin features in the head and trunk, it is necessary to separate the front and back of the limbs in the coronal plane. Thus the manganin heating wire and alumel measurement wire were distributed over the following 20 parts: anterior head, posterior head, ventral trunk, dorsal trunk (including buttocks), right medial arm, right lateral arm, left medial arm, left lateral arm, right dorsal hand, right palmar hand, left dorsal hand, left palmar hand, right anterior leg, right posterior leg, left anterior leg, left posterior leg, right dorsal foot, right plantar foot, left dorsal foot, and left plantar foot.

It is essential for the surface of the humanoid model to develop the skin temperature to have as uniform a temperature as possible on the surface of each body part. Here, the surface of each layer was covered with a material with high heat conductivity and electric insulation (Sumitomo Osaka Cement Co., Ltd.: Zimainus X2, heat conductivity $2.4 \mathrm{~W} /(\mathrm{m} \cdot \mathrm{K})$ ) [97]. Each layer was about $1 \mathrm{~mm}$ thick. Then, from the $3 \mathrm{D}$ skin data of the $3 \mathrm{D}$ modeled humanoid we made a humanoid model with a $2 \mathrm{~mm}$ offset in cross-section. Since there is a limit to the recovery redaction of 3D skin data, the polygon data was adjusted using Rhinoceros (AppliCraft Co., Ltd.: Rhinoceros) [98] and Autodesk Meshmixer (Autodesk Inc.: Autodesk Meshmixer) [99].

The 3D modeled humanoid was rendered on a 3D printer (Zortrax: Zortrax M300, Layer resolution 90 - 290 microns, nozzle diameter $0.4 \mathrm{~mm}$ ) [100]. High impact polystyrene was used as the $3 \mathrm{D}$ printer filament resin. Figure 1 shows the modeled thermal manikin. 


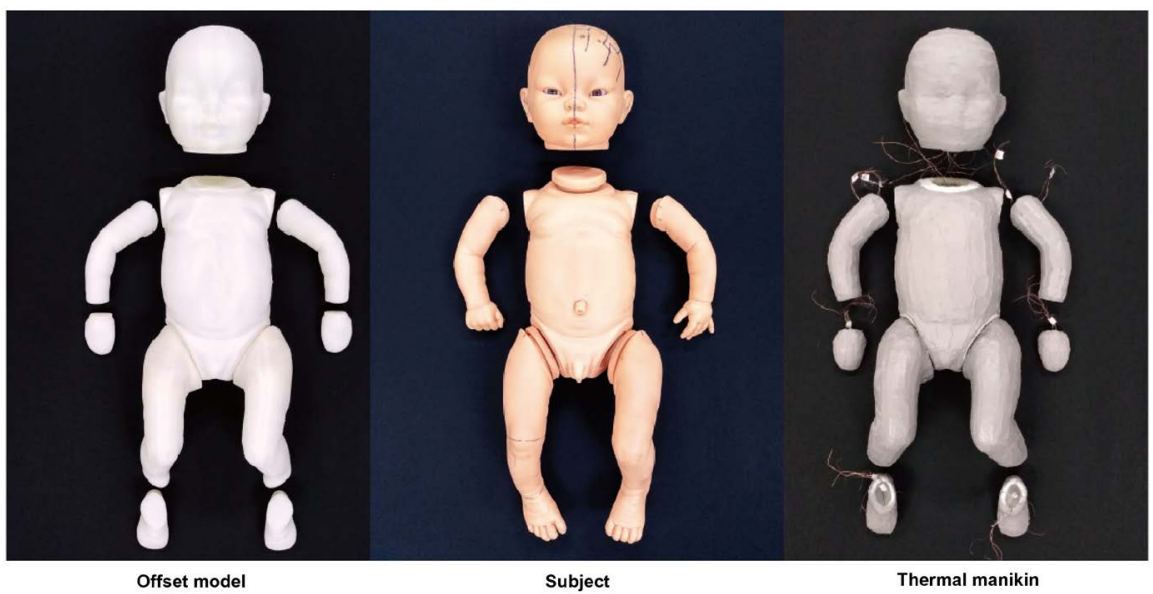

Figure 1. Thermal manikin.

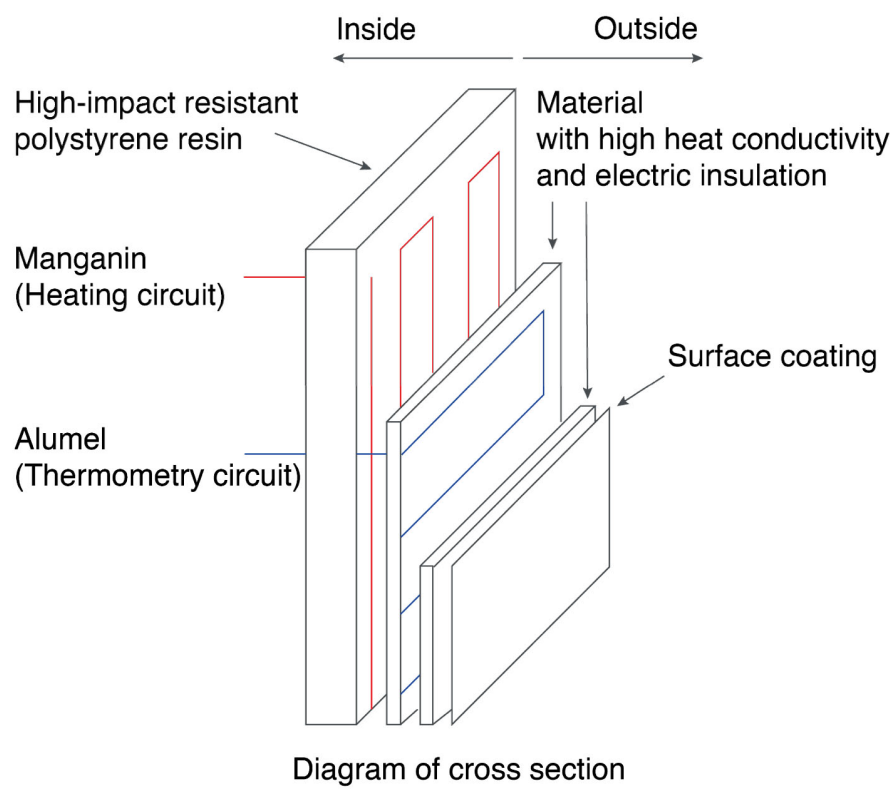

Figure 2. Structure of thermal mannequin.

\section{Effectiveness of the Infant Thermal Manikin}

We evaluated the effectiveness of the infant thermal manikin from the perspective of the heat transfer area, similar to that in part 5. Body surface area was directly measured by attaching surgical tape directly to the body surface and calculating the area of the tape [53] [54] [55] [56] [57].

Table 4 shows the measurements for the body surface area of each part of the infant thermal manikin. There was no large left-right difference in the limbs. Therefore, the humanoid form can be said to be an effective infant thermal manikin regarding the unevenness and asymmetry of the temperature of the skin, as an element of the human body. The body surface area ratio for each of the main body parts of the infant thermal manikin, namely the head, trunk (including buttocks), arm, hand, leg and foot, was $0.240,0.285,0.120,0.039,0.258$, and 0.058 respectively. Comparison of these results with the data shown in Table 2 
Table 4. Results of body surface are.

\begin{tabular}{cccccc}
\hline Reagion & $\begin{array}{c}\text { Surface area } \\
{\left[\mathrm{cm}^{2}\right]}\end{array}$ & Area ratio [-] & Area ratio [-] & Area ratio [-] & Area ratio [-] \\
\hline Anterior head & 352.99 & 0.157 & 0.240 & 0.240 & 0.240 \\
Posterior head & 187.97 & 0.083 & & & 0.285 \\
\hline Ventral trunk & 316.41 & 0.141 & 0.285 & 0.285 & \\
Dorsal trunk & 324.69 & 0.144 & & & 0.159 \\
\hline Right medial arm & 54.39 & 0.024 & 0.060 & 0.120 & \\
Right lateral arm & 79.88 & 0.036 & & & \\
Left medial arm & 54.48 & 0.024 & 0.060 & & \\
Left lateral arm & 81.67 & 0.036 & & & \\
\hline Right dorsal hand & 24.60 & 0.011 & 0.020 & 0.039 & \\
Right palmar hand & 19.51 & 0.009 & & & \\
Left dorsal hand & 23.80 & 0.011 & 0.019 & & \\
Left palmar hand & 18.99 & 0.008 & & & \\
\hline Right anterior leg & 158.52 & 0.070 & 0.128 & 0.258 & \\
Right posterior leg & 131.23 & 0.058 & & & \\
Left anterior leg & 155.25 & 0.069 & 0.130 & & \\
Left posterior leg & 136.64 & 0.061 & & & \\
\hline Right dorsal foot & 32.57 & 0.015 & 0.030 & & \\
Right planter foot & 34.75 & 0.015 & & & \\
Left dorsal foot & 30.23 & 0.013 & 0.028 & & \\
Left planter foot & 34.22 & 0.015 & & & \\
\hline & & & & \\
\hline
\end{tabular}

shows that the body surface area of the lower limbs increased slightly, but was still within the range of actual measurements in previous studies. Therefore, the validity of modeling an infant thermal manikin has been verified.

\section{Conclusion}

We cannot ethically conduct experiments on infant subjects to evaluate the thermal environment based on the heat balance of their bodies. Here, we developed a thermal manikin modeling the heat transfer area and the body form of an infant in order to evaluate the thermal environment for an infant. This paper measured the body surface area for each part of an infant's body in order to establish the form of an infant model from the perspective of the heat transfer area, and verified the validity of the model.

\section{Acknowledgements}

We would like to express our sincerest gratitude to the people who cooperated in the experiment and measurements. This work was supported by JSPS KAKENHI Grant number JP18H01594. 


\section{Conflicts of Interest}

The authors declare no conflicts of interest regarding the publication of this paper.

\section{References}

[1] Ministry of the Environment Government of Japan (2019) Outline of the Policy Framework to Reduce Urban Heat Island Effects. Decided in March 2004. https://www.env.go.jp/en/air/heat/heatisland.pdf

[2] Kurazumi, Y., Fukagawa, K., Yamato, Y., Tobita, K., Kondo, E., Tsuchikawa, T., Horikoshi, T. and Matsubara, N. (2011) Enhanced Conduction-Corrected Modified Effective Temperature as the Outdoor Thermal Environment Evaluation Index upon the Human Body. Building and Environment, 46, 12-21. https://doi.org/10.1016/j.buildenv.2010.06.012

[3] Kurazumi, Y., Tsuchikawa, T., Matsubara, N., Kondo, E. and Horikoshi, T. (2011) Evaluation of Enhanced Conduction-Corrected Modified Effective Temperature ETFe as the Outdoor Thermal Environment Evaluation Index. Energy and Buildings, 43, 2925-2937. https://doi.org/10.1016/j.enbuild.2011.07.019

[4] Kurazumi, Y., Kondo, E., Ishii, J., Sakoi, T., Fukagawa, K., Bolashikov, Z.D., Tsuchikawa, T., Matsubara, N. and Horikoshi, T. (2013) Effect of the Environmental Stimuli upon the Human Body in Winter Outdoor Thermal Environment. Journal of Environmental and Public Health, 2013, Article ID: 418742. https://doi.org/10.1155/2013/418742

[5] Kurazumi, Y., Ishii, J., Fukagawa, K. and Aruninta, A. (2015) The Influence of Tropical Urban Climate upon the Human Body. International Joint-Conference of SENVAR-iNTA-AVAN 2015 (SIA 2015), Johor, Malaysia, 24-26 November 2015, 105-114.

[6] Kurazumi, Y., Ishii, J., Fukagawa, K., Kondo, E. and Aruninta, A. (2016) Ethnic Differences in Thermal Responses between Thai and Japanese Females in Tropical Urban Climate. American Journal of Climate Change, 5, 52-68. https://doi.org/10.4236/ajcc.2016.51007

[7] Kurazumi, Y., Ishii, J., Fukagawa, K., Kondo, E., Nyilas, A. and Aruninta, A. (2017) Seasonal Differences of Psychological and Physiological Responses in Tropical Urban Climate. Health, 9, 896-920. https://doi.org/10.4236/health.2017.96064

[8] Iriki, M. (1995) Taion cyosetu no shikumi, 249. Bunkodo Co., Ltd., Tokyo, Japan. (In Japanese)

[9] Nakayama, A. and Iriki, M. (1987) Shin seirikagaku taikei 22, Enerugi taisya-taion cyosetu no seirigaku. Igaku-Shoin Ltd., Tokyo, Japan, 60-61. (In Japanese)

[10] Bar-Or,O. (1980) Climate and the Exercising Child-A Review. International Journal of Sports Medicine, 1, 53-65. https://doi.org/10.1055/s-2008-1034631

[11] Shiraishi, T. and Araki, T. (1990) Comparative Study on Thermoregulation under Heat Exposure between Children and Adults-With Special Reference to Sweating and Skin Temperature Reactions. Japanese Journal of School Health, 32, 134-143.

[12] Tochihara, Y., Ohnaka, T. and Nagai, Y. (1995) Thermal Responses 6- to 8-YearOld Children during Immersion of Their Legs in a Hot Water Bath. Applied Human Science, 14, 23-28. https://doi.org/10.2114/ahs.14.23

[13] Delamarche, P., Bittel, J., Lacour, J.R. and Flandrois, R. (1990) Thermoregulation at Rest and during Exercise in Prepubertal Boys. European Journal of Applied Physiology and Occupational Physiology, 60, 436-440. 
https://doi.org/10.1007/BF00705033

[14] Ogawa, T. (1996) Exercise and Sweating. Japanese Journal of Physical Fitness and Sports Medicine, 45, 289-300. https://doi.org/10.7600/jspfsm1949.45.289

[15] Sugiura, H., Kinoshita, H. and Fujimoto, T. (2011) Questionnaire Investigation on the Infant's Sweat in Four Seasons. The Journal of Child Health, 70, 535-541.

[16] Wagner, J.A., Robinson, S. and Marino, R.P. (1974) Age and Temperature Regulation of Humans in Neutral and Cold Environments. Journal of Applied Physiology, 37, 562-565. https://doi.org/10.1152/jappl.1974.37.4.562

[17] Haymes, E.M., McGormick, R.J. and Buskirk, E.R. (1975) Heat Tolerance of Exercising Lean and Obese Prepubertal Boys. Journal of Applied Physiology, 39, 457461. https://doi.org/10.1152/jappl.1975.39.3.457

[18] Drinkwater, B.L., Kupprat, I.C., Denton, J.E., Crist, J.L. and Horvath, S.M. (1977) Response of Prepubertal Girls and College Women to Work in the Heat. Journal of Applied Physiology, 43, 1046-1053. https://doi.org/10.1152/jappl.1977.43.6.1046

[19] Araki, T., Toda, Y., Inoue, Y. and Tsujino, A. (1979) Age Differences in Sweating during Muscular Exercise. Journal of Physical Fitness and Sports Medicine, 28, 239-248. https://doi.org/10.7600/jspfsm1949.28.239

[20] Tsuzuki, K. (1998) Thermoregulation during Hot and Warm Exposures of Infants Compared to Their Mothers. Journal of Home Economics of Japan, 49, 409-415.

[21] Tsuzuki, K., Ohnaka, T. and Tochihara, Y. (1998) Seasonal Variation and Age Difference in Thermal Responses under Preferred Temperatures Determined by the Mothers. Journal of Home Economics of Japan, 49, 1109-1117.

[22] Aritomi, Y., Horikoshi, T. and Uno, Y. (2009) The Influence of Room Heating Characteristics on the Physiological Reaction of Young Children and Their Mother, Comparison of Local Skin Temperatures, Variation of Types of Heat Diffusion Present and Calculation of Convective Heat Transfer Coefficients. Journal of Environmental Engineering (Transactions of AI), 74, 315-321.

https://doi.org/10.3130/aije.74.315

[23] Tsuzuki, K., Iizuka, S., Mitsutuji, S., Ikeda, A., Tomita, J., Tochihara, Y. and Ohnaka, T. (2001) Typical Thermal Environment for Young Children Dwelling in and around the Tokyo Metropolitan Area. Journal of Home Economics of Japan, 52, 429-438.

[24] Fukazawa, T., Ikeda, S., Kim, S. and Tochihara, Y. (2009) Seasonal Clothing Variation and Thermal Resistance of Clothing Ensembles of Infants Living in Kyushu. Journal of Home Economics of Japan, 60, 635-643.

[25] Aritomi, Y. and Horikoshi, T. (2009) Questionnaire Survey of Summer Indoor Environments and Occupants' Body Temperature Regulation in Residential Buildings with Young Children. Japanese Journal of Biometeorology, 46, 13-25.

[26] Wissler, E.H. (1961) Steady-State Temperature Distribution in Man. Journal of Applied Physiology, 16, 734-740. https://doi.org/10.1152/jappl.1961.16.4.734

[27] Atkins, A.R. and Wyndham, C.H. (1969) A Study of Temperature Regulation in the Human Body with the Aid of an Analogue Computer. Pflugers Archiv, 307, 104-119. https://doi.org/10.1007/BF00586467

[28] Gagge, A.P., Stolwijk, J.A.J. and Nishi, Y. (1971) An Effective Temperature Scale Based on a Simple Model of Human Physiological Regulatory Response. ASHRAE Transactions, 77, 247-262.

[29] Gagge, A.P., Nishi, Y. and Nevins, R.G. (1977) The Role of Clothing in Meeting FEA Energy Conversation Guidelines. ASHRAE Transactions, 82, 234-247. 
[30] Gagge, A.P., Fobelets, A.P. and Bergund, L.G. (1986) A Standard Simulated Index of Human Response to the Thermal Environment. ASHRAE Transactions, 92, 709731.

[31] Stolwijk, J.A.J. and Hardy, J.D. (1966) Temperature Regulation in Man: A Theoretical Study. Pflugers Archiv, 291, 129-162.

[32] Stolwijk, J.A.J. (1971) A Mathematical Model of Physiological Temperature Regulation in Man. NASA-Langley, CR-1855.

[33] Smith, C.E. (1933) A Transient, Three-Dimensional Model of the Human Thermal System. Ph.D. Dissertation, Kansas State University, Manhattan, KS.

[34] Takemori, T., Nakajima, T. and Shoji, Y. (1995) A Kansas Fundamental Model of the Human Thermal System for Simulation of Thermal Comfort. Transactions of the Japan Society of Mechanical Engineers, 61, 297-304. https://doi.org/10.1299/kikaib.61.1513

[35] Fu, G. (1995) A Transient, 3-D Mathematical Thermal Model for Clothed Human, Kansas State University, Manhattan, KS.

[36] Yokoyama, S., Kakuta, N., Togashi, T., Hamada, Y., Nakamura, M. and Ochifuji, K. (2000) Development of Simulation Computer Program of Whole Body Temperatures expressing Local Characteristic of Each Segment, Part 1-Bio-Heat Equations and Solving Method. Transactions of the Society of Heating, Air-Conditioning and Sanitary Engineers of Japan, 77, 1-12.

[37] Yokoyama, S., Kakuta, N., Togashi, T., Hamada, Y., Nakamura, M. and Ochifuji, K. (2001) Development of Simulation Computer Program of Whole Body Temperatures Expressing Local Characteristic of Each Segment, Part 2-Analysis of the Mathematical Model for the Control of Skin Blood Flow. Transactions of the Society of Heating, Air-Conditioning and Sanitary Engineers of Japan, 78, 1-8.

[38] Yokoyama, S., Kakuta, N., Togashi, T., Nakamura, M., Masaki, T., Hamada, Y., Nakamura, M. and Ochifuji. K. (2002) Development of Simulation Computer Program of Whole Body Temperatures Expressing Local Characteristic of Each Segment, Part 3-A Comparison of Experimental and Calculated Results of Body Temperatures. Transactions of the Society of Heating, Air-Conditioning and Sanitary Engineers of Japan, 84, 43-52.

[39] Tanabe, S., Nakano, J. and Kobayashi, S. (2001) Development of 65-Node Thermoregulation-Model for Evaluation of Environment. Journal of Architecture and Planning (Transactions of AI), 541, 9-16. https://doi.org/10.3130/aija.66.9_2

[40] Huizenga, C., Hui, Z. and Arens, E. (2001) A Model of Human Physiology and Comfort for Assessing Complex Thermal Environments. Buildings and Environment, 36, 691-699. https://doi.org/10.1016/S0360-1323(00)00061-5

[41] McGuffin, R., Burke, R., Huizenga, C., Hui, Z., Vlahinos, A. and Fu, G. (2002) Human Thermal Comfort Model and Manikin. SAE Technical Papers 2002-01-1955, SAE Future Car Congress, Arlington, VI. https://doi.org/10.4271/2002-01-1955

[42] Kohri, I. and Mochida, T. (2003) Simulation Method of Regional Skin Temperature with Dispersed Two-Node Model. Transactions of the Society of Heating, Air-Conditioning and Sanitary Engineers of Japan, 88, 73-82.

[43] Ozeki, Y., Hiramatsu, T. and Tanabe, S. (2004) Comparison of Skin Surface Temperatures between Subjective Experiments and Numerical Simulated by Using a Modified 65MN Thermoregulation Model under solar Radiation. Journal of Environmental Engineering (Transactions of AIJ), 581, 29-36. https://doi.org/10.3130/aije.69.29_3

[44] Sakoi, T., Tsuzuki, K., Kato, S., Ooka, R., Song, D. and Zhu, S. (2007) Study on 
Evaluation Method for Non-Uniform Thermal Environment, Part 3-Expression of Thermal Comfort in Sitting People in Terms of Local Skin Temperatures and Local Dry Heat Losses. Transactions of the Society of Heating, Air-Conditioning and Sanitary Engineers of Japan, 126, 1-10.

[45] Kuwabara, K., Kubota, H., Hamada, Y., Nakamura, M., Nakaya, N., Amemiya, S. and Nagano, K. (2009) Simulation of Mean Skin Temperature in Hot Outdoor Environment Considering Sweat Efficiency and Wet Clothing. Transactions of the Society of Heating, Air-Conditioning and Sanitary Engineers of Japan, 144, 1-10.

[46] Park, S. and Tuller, S.E. (2011) Comparison of Human Radiation Exchange Models. Theoretical and Applied Climatology, 105, 357-370. https://doi.org/10.1007/s00704-010-0388-2

[47] Kurazumi, Y., Sakoi, T., Tsuchikawa, T., Fukagawa, K., Bolashikov, Z.D., Horikoshi, T. (2014) Behavioral Thermoregulation Model for Evaluation of Outdoor Thermal Environment. Journal of Ergonomics, 4, 1-14. https://doi.org/10.4172/2165-7556.1000125

[48] Kyoto Electronics Manufacturing Co., Ltd. (2019) Thermal Manikin. https://www.kyoto-kem.com/ja/product/thmms/

[49] Measurement Technology North West, Thermetrics (2019) Full Body Manikins. http://www.thermetrics.com/products/full-body-manikins

[50] Intec Co., Ltd. (2019) Thermal Manikin. http://www.intec-instruments.co.jp/jigyo/setubi/doc/itm.pdf

[51] Teknik, P.T. (2019) Thermal Manikin. http://pt-teknik.dk

[52] Fukazawa, T., Tochihara, Y., Yamamoto, T., Holmér, I. and Kuklane, K. (2005) Usability of a Newly Developed Thermal Manikin of Infant to Assess Thermal Stress in Various Environments. Proceedings of the 11 th International Conference of Environmental Ergonomics, Lund, Sweden, 22-26 May 2005, 618-619.

[53] Kurazumi, Y., Tsuchikawa, T., Yamato, Y., Kakutani, K., Matsubara, N. and Horikoshi, T. (2003) The Posture and Effective Thermal Convection Area Factor of the Human Body. Japanese Journal of Biometeorology, 40, 3-13.

[54] Kurazumi, Y., Tsuchikawa, T., Matsubara, M. and Horikoshi, T. (2004) Convection Heat Transfer Area of the Human Body. European Journal of Applied Physiology, 93, 273-285. https://doi.org/10.1007/s00421-004-1207-1

[55] Kurazumi, Y., Tsuchikawa, T., Matsubara, N. and Horikoshi, T. (2008) Effect of Posture on the Heat Transfer Areas of the Human Body. Building and Environment, 43, 1555-1565. https://doi.org/10.1016/j.buildenv.2007.09.001

[56] Kurazumi, Y., Horikoshi, T., Tsuchikawa, T. and Matsubara, N. (1994) The Body Surface Area of Japanese. Japanese Journal of Biometeology, 31, 5-29.

[57] Kurazumi, Y., Tsuchikawa, T., Kakutani, K., Torii, T., Matsubara, N. and Horikoshi, T. (2003) Evaluation of the Conformability of the Calculation Formula for the Body Surface Area of the Human Body. Japanese Journal of Biometeorology, 39, 101-106.

[58] Suzuki, K. and Kakitsuba, N. (1999) Development of a Human Body Model Based on The Human Body Area and the Configuration Factors. Journal of Architecture, Planning and Environmental Engineering (Transactions of AI), 515, 49-55. https://doi.org/10.3130/aija.64.49

[59] Ozeki, Y., Konishi, M., Narita, C. and Tanabe, S. (1999) Evaluation on Effective Radiation Area of Human Body Calculated by a Numerical Simulation. Journal of Architecture, Planning and Environmental Engineering (Transactions of AI), 525, 45-51. https://doi.org/10.3130/aija.64.45_6 
[60] Manabe, M., Yamazaki, H. and Kojima, S. (2002) Shape Factor Calculation for Human Body Using Scan Line. Journal of Architecture, Planning and Environmental Engineering (Transactions of AI), 551, 37-44. https://doi.org/10.3130/aija.67.37_1

[61] Omori, T., Jeonghoon, Y., Kato, S. and Murakami, S. (2003) Radiative Heat Transfer Analysis Method for Coupled Simulation of Convection and Radiation in LargeScale and Complicated Enclosures, Part 1: Accurate Radiative Heat Transfer Analysis Based on Monte Carlo Method. Transactions of the Society of Heating, Air-Conditioning and Sanitary Engineers of Japan, 88, 103-113.

[62] Sørensen, D.N. and Voigt, L.K. (2003) Modeling Flow and Heat around a Seated Human Body Computational Fluid Dynamics. Building and Environment, 38, 753-762. https://doi.org/10.1016/S0360-1323(03)00027-1

[63] Torii, T., Kurazumi, Y., Tsuchikawa, T., Yamato, Y. and Matsubara, N. (2003) Three-Dimensional Human Body Surface Model in Consideration of the Heat Transfer Area. Journal of Human and Living Environment, 10, 91-97.

[64] Ito, K. and Hotta, T. (2006) Development of Virtual Manikins and Its Grid Library Fir CFD Analysis. Transactions of the Society of Heating, Air-Conditioning and Sanitary Engineers of Japan, 113, 37-44.

[65] Kurazumi, Y., Tsuchikawa, T., Fukui, R., Torii, T., Fukagawa, K., Ishii, J., Yamato, Y. and Matsubara, N. (2007) Human Body Surface Model in the Chair Sitting Position Based on the Heat Transfer Areas. Journal of Human and Living Environment, 14, 1-9.

[66] Fanger, P.O., Angelius, O. and Jensen, P.K. (1970) Radiation Data for the Human Body. ASHRAE Transactions, 76-II, 338-373.

[67] Tsuchikawa, T., Horikoshi, T., Kondo, E., Kurazumi, Y., Hirayama, K. and Kobayashi, Y. (1991) The Effective Radiation Area of the Human Body and Configuration Factors between the Human Body and Rectangular Planes and Measured by the Photographic Method, Part 2 Measurement for a Female and for the Surface-Parts of a Male Body. Journal of Architecture, Planning and Environmental Engineering (Transactions of AIJ), 428, 67-75. https://doi.org/10.3130/aijax.428.0_67

[68] Nihon 3B Scientific Inc. (2019) Nurse Training Baby, Asian Body Care Model Male, W17002. https://www.3bs.jp/simulator/child/w17002-w17003.htm

[69] Funke, O. (1858) Beiträge zur kenntniss der schweisssecretion. Moleschtt’s Untersuchungen zur Naturlehre des Menschen, 4, 36-57.

[70] DuBois, D. and DuBois, E.F. (1916) Clinical Calorimetry Fifth Paper a Formula to Estimate the Approximate Surface Area if Height and Weight Be Known. Archives of Internal Medicine, 17, 863-871. https://doi.org/10.1001/archinte.1916.00080130010002

[71] DuBois, D. and DuBois, E.F. (1915) Clinical Calorimetry Fifth Paper the Measurement of the Surface Area of Man. Archives of Internal Medicine, 15, 868-881. https://doi.org/10.1001/archinte.1915.00070240077005

[72] Sawyer, M., Stone, R.H. and DuBois, E.F. (1916) Clinical Calorimetry Ninth Paper Further Measurement of the Surface Area of Adults and Children. Archives of Internal Medicine, 17, 855-862.

https://doi.org/10.1001/archinte.1916.00080130002001

[73] Fujimoto, S., Watanabe, T., Sakamoto, A., Yukawa, K. and Morimoto, K. (1968) Studies on the Physical Surface Area of Japanese, Part18 Calculation Formulas in Three Stages over All Age. Japanese Journal of Hygiene, 23, 443-450. https://doi.org/10.1265/jih.23.443

[74] Architectural Institute of Japan (2014) Architectural Institute of Japan Environmen- 
tal Standards AIJES-H0004-2014, Standards for Measurement of Psychological and Physiological Responses to Thermal Environments. Architectural Institute of Japan, Tokyo, Japan.

[75] Meeh, K. (1879) Ober flächenmessungen des menschlichen körpers. Zeitschrift für Biologie, 15, 425-458.

[76] Lissauer, W. (1903) Ueber oberflächenmessungen un säuglingen und ihre bedeutung für den nahrungsbedarf. Jahrbuch für Kinderheilkunde und Physische Erziehung. N.F., 58, 392-411.

[77] Lassabliére, P. (1910) Evaluation de la surface cutanée chez le jeune enfant. Comptes rendus hebdomadaires des séances et mémoires de la société de biologie, 59, 339-341.

[78] Klein, A.D. and Scammon, R.E. (1930) The Regional Growth in Surface Area of the Human Body in Prenatal Life. Proceedings of the Society for Experimental Biology and Medicine, 27, 463-466. https://doi.org/10.3181/00379727-27-4809

[79] Otani, K. (1907) Nihon syoni no taihyo menseki sokutei. Tokyo igakkai zasshi, 21, 89-117. (In Japanese)

[80] Oshiro, C. and Tagawa, T. (1936) Nihon nyuji no taihyo menseki sokutei seiseki. Nika zasshi, 43, 604-616. (In Japanese)

[81] Ochi, T. and Higuchi, T. (1935) On the Body Surface Measurements and Normal Standard of Basal Metabolism of New Born Infants. Keio igaku, 15, 709-725. (In Japanese)

[82] Kawabata, M. (1940) Isshin taihyo menseki keisan shiki. Nihon seiri gakkai zasshi, 5, 245-254. (In Japanese)

[83] Kobayashi, O., Washio, S., Kodama, T., Sakaguchi, S. and Hayashi, I. (1952) Honpo syoni no taihyo menseki ni tuite. Nihon syonika gakkai zasshi, 56, 217-221. (In Japanese)

[84] Miyajima, T. (1960) Nihon jin no taihyo menseki ni kansuru kenkyu, Dai 13 nyuji no taihyo menseki oyobi sono sansyutu shiki. Nagasaki sogo kosyu eiseigaku zasshi, 9, 484-499. (In Japanese)

[85] Fujimoto, S., Watanabe, T., Yukawa, K. and Saksamoto, A. (1968) Studies on the Physical Surface Area of Japanese, Part 17 Regional Rates According to Sex, Age and Body Shape. Japanese Journal of Hygiene, 23, 437-442. (In Japanese) https://doi.org/10.1265/jjh.23.437

[86] Kawagoe, T. (1958) Nihon jin no taihyo menseki ni kansuru kenkyu, Dai 7 hen 4 sai-5 sai no taihyo menseki oyobi sono sansyutu shiki. Nagasaki sogo kosyu eiseigaku zasshi, 7, 213-229. (In Japanese)

[87] Matsuo, S. (1959) Nihon jin no taihyo menseki ni kansuru kenkyu, Dai 10 hen 3 sai-4 sai no taihyo menseki oyobi sono sansyutu shiki. Nagasaki sogo kosyu eiseigaku zasshi, 8, 428-440. (In Japanese)

[88] Koashi, A. (1959) Nihon jin no taihyo menseki ni kansuru kenkyu, Dai 12 hen 1 sai 1 kagetu-1 sai 6 kagetu no taihyo menseki oyobi sono sansyutu shiki. Nagasaki sogo kosyu eiseigaku zasshi, 8, 428-440. (In Japanese)

[89] Fujiwara, K. (1960) Nihon jin no taihyo menseki ni kansuru kenkyu, Dai 14 hen 2 sai-3 sai no taihyo menseki oyobi sono sansyutu shiki. Nagasaki sogo kosyu eiseigaku zasshi, 9, 500-516. (In Japanese)

[90] Ministry of Health, Labour and Welfare, Japan (2019) National Growth Survey on Preschool Children. https://www.mhlw.go.jp/toukei/list/dl/73-22-01.pdf

[91] Boyd, E. and Scammon, R.E. (1930) The Relation of Surface Area Body Weight in Postnatal Life. Proceedings of the Society for Experimental Biology and Medicine, 
27, 449-453. https://doi.org/10.3181/00379727-27-4804

[92] Horikoshi, T., Kurazumi, Y., Hirayama, K., Tsuchikawa, T. and Kobayashi, Y. (1989) Indication of the Effect of Asymmetric Thermal Radiation of the Human Physiological and Psychological Responses. The Second World Congress on Heating, Ventilating, Refrigerating and Air Conditioning-CLIMA 2000 III, Sarajevo, Yugoslavia, 27 August-1 September 1989, 188-193.

[93] Kurazumi, Y., Saito, K. and Horikoshi, T. (1994) The Influence of Asymmetric Thermal Radiation Environments upon the Human Body, in the Case of Constant Operative Temperature and Right and Left, Back and Forth Asymmetry. Japanese Journal of Biometeorology, 31, 75-84.

[94] Kurazumi, Y., Horikoshi, T., Hirayama, K., Tsuchikawa, T. and Kobayashi, Y. (1993) The Influence of Asymmetric and Uneven Thermal Radiation Environments upon the Human Body, in the Case of Constant Operative Temperature. Journal of Architecture, Planning and Environmental Engineering (Transactions of A.I.J.), 447, 17-26. https://doi.org/10.3130/aijax.447.0_17

[95] SHINING 3D (2019) EinScan-S. http://en.shining3d.com/digitizer_detail-4476.html

[96] Kurazumi, Y., Fukagawa, K., Sakoi, T., Aruninta, A., Kondo, E. and Yamashita, K. (2018) Skin Temperature and Body Surface Section in Non-Uniform and Asymmetric Outdoor Thermal Environment. Health, 10, 1321-1341.

https://doi.org/10.4236/health.2018.1010102

[97] Sumitomo Osaka Cement Co., Ltd. (2019) Zi-mainus X2.

http://www.soc-tec.com/z-ma/

[98] AppliCraft Co., Ltd. (2019) Rhinoceros. https://www.applicraft.com/products/rhinoceros/rhinoceros/

[99] Autodesk Inc. (2019) Autodesk Meshmixer. http://www.meshmixer.com

[100] Zortrax (2019) Zortrax M300, Layer Resolution 90 - $290 \mu \mathrm{m}$, Nozzle Diameter 0.4 mm. https://zortrax.com/3d-printers/m300-plus/ 